\title{
The Activity of Antioxidative Enzymes of Neutrophils in Patients with Unfavorable Outcome of Acute Coronary Syndrome
}

\author{
Andrey Kratnov, Elena Timganova \\ Department of Therapy of Yaroslavl State Medical University, Yaroslavl, Russia \\ Email: kratnov@mail.ru
}

Received 18 March 2015; accepted 24 April 2015; published 27 April 2015

Copyright (C) 2015 by authors and Scientific Research Publishing Inc.

This work is licensed under the Creative Commons Attribution International License (CC BY). http://creativecommons.org/licenses/by/4.0/

\section{c) (i) Open Access}

\begin{abstract}
Background: There is a necessity for an establishment of specific markers of oxidative stress for screening in populations of high risk and an estimation of efficiency antioxidative therapies. Objective: Studying the activity of antioxidative enzymes at neutrophils in patients with acute coronary syndrome depending on outcome during the year. Methods: Intracellular metabolism of neutrophils was studied in 108 patients, of whom, in 58 persons has been diagnosed acute coronary syndrome, and 50 individuals were without coronary heart disease. Results: In patients with acute coronary syndrome, in comparison with patients without coronary heart disease, growth of production of superoxide anion on background reduction of glutathione reductase activity in neutrophils was revealed. The greatest reduction in parameters of glutathione reductase and catalase at simultaneous growth of activity of NAD(P)H oxidase and myeloperoxidase at neutrophils was observed in patients with fatal outcome during the year. Conclusion: The decrease of efficiency antioxidative protection of neutrophils associates with risk of fatal outcome in patients with acute coronary syndrome.
\end{abstract}

\section{Keywords}

Antioxidance, Reactive Forms of Oxygen, Neutrophils, Acute Coronary Syndrome

\section{Introduction}

Despite of presence convincing proofs that free radicals play an important role in development of atherosclerotic defeat, till now does not exist standard marker of oxidative stress and estimation of efficiency of antioxidant defence at cardiovascular diseases [1]. There are proofs, that the increase in peripheral blood of neutrophils which play an important role in reperfusion damage of myocardium is prognostic risk marker of cardiac death [2] [3].

How to cite this paper: Kratnov, A. and Timganova, E. (2015) The Activity of Antioxidative Enzymes of Neutrophils in Patients with Unfavorable Outcome of Acute Coronary Syndrome. Natural Science, 7, 227-231. 
In the recent years was revealed association the changes of intracellular metabolism of neutrophils with development of endothelial dysfunction which also is risk marker of fatal outcome at coronary heart disease [4] [5].

The objective was to study the activity of antioxidative enzymes at neutrophils in patients with acute coronary syndrome depending on outcome during the year.

\section{Participants and Methods}

\subsection{Participants}

The study included 58 patients with acute coronary syndrome aged 34 to 85 years (mean \pm SD age: $62.5 \pm 10$ years), of them, 31 (53.4\%) patients had unstable angina and 27 (46.6\%) had acute myocardial infarction. 50 patients without coronary heart disease aged 18 to 69 years (mean \pm SD age: $42.2 \pm 13.4$ years) which were hospitalized in hospital for professional survey have been examined. In order to exclude coronary heart disease in all patients, the electrocardiography was performed, along with bicycle ergometry, Holter electrocardiography monitoring, and echocardiography.

The patients with acute coronary syndrome were followed for 12 months from the date of entry into the study. Cases of repeated anginal attacks at rest (unstable angina), repeated or new nonfatal myocardial infarction, and cardiac death were recorder.

\subsection{Methods}

The material for this study was performed at admission of patients to the hospital with the consent of the Ethical Committee. Analysis of peripheral blood was performed at admission to the cardiology intensive care unit. Neutrophils were isolated from heparinised blood in Ficoll-Verographin double density gradient 1.077 and 1.092 $\mathrm{g} / \mathrm{cm}^{3}$. The second interface cells contained $95 \%$ of neutrophils. The number of neutrophils in the cell suspension was counted in a cell with Goryaev vivo staining with methylene blue in $3 \%$ acetic acid (Turk dye) to determine viable cells. Cell viability, estimated by trypan blue, was more than $90 \%$. The cell suspension was diluted with medium 199, adjusting the concentration of $5 \times 10^{6}$ neutrophils per $1 \mathrm{ml}$. The final result was calculated per $1 \times 10^{6}$ neutrophils, proceeding from the amount of $5 \times 10^{6}$ cells in the studied suspension.

The test of spontaneous and stimulated nitroblue tetrasolium reduction (NBT-test) was performed by means of quantitative spectrophotometric method of Gentle T. A. \& Thompson R. A. [6] using $0.2 \%$ nitro blue tetrasolium in phosphate buffer $\mathrm{pH} 7.2$, fixing neutrophils with methanol and solubilising reduced diformasan in $2 \mathrm{M}$ potassium hydroxide and dimethylsulfoxide 3:5 volume mixture. The calibration was performed by direct solubilisation of nitroblue tetrasolium in potassium hydroxide and dimethylsulfoxide at same ratio. The photometry was performed at $495 \mathrm{~nm}$ wavelength using spectrophotometer. For evaluation of neutrophils C3-receptor activity, suspension of phytohemagglutinin (Phaseolus vulgaris, "PanEco", USA) was used. The suspension was added to the cuvettes with neutrophils in amount of $0.2 \mathrm{ml}$ for activated NBT-test.

Myeloperoxidase activity in neutrophils was studied using a $0.04 \%$ solution ortofenilendiamin in phosphate buffer $\mathrm{pH} 5.0$, with the addition of $0.33 \%$ hydrogen peroxide solution at a ratio of $20: 1$ by volume. The reaction was stopped after 10 minutes of $10 \%$ sulphuric acid solution. The photometry was performed at $492 \mathrm{~nm}$ [7].

The determination of glutathione reductase activity in neutrophils was evaluated by method on degree of oxidation of NADH. In the control and skilled tests containing $0.5 \mathrm{ml}$ of suspension neutrophils $1.5 \mathrm{ml}$ of distilled water, $0.1 \mathrm{ml} \mathrm{NADH}$ and $0.3 \mathrm{ml}$ buffer $\mathrm{pH} 8$ was added. The reaction started by addition $0.2 \mathrm{ml}$ of $0.033 \mathrm{mM}$ solution oxidized glutathione. The tests were left at temperature $37^{\circ} \mathrm{C}$ for 30 minutes. To stop the reaction the test was placed in refrigerator for 10 minutes at temperature $4^{\circ} \mathrm{C}$. The photometry was performed at $340 \mathrm{~nm}$ [8].

The determination of catalase activity in neutrophils was based on the ability of hydrogen peroxide to form salts with molybdenum stable colored complex. The reaction was run by adding $0.03 \%$ hydrogen peroxide solution and was stopped after 10 minutes, adding a $4 \%$ solution of ammonium molybdate. In control test instead of neutrophils distilled water was brought. The color intensity was measured at $\lambda=410 \mathrm{~nm}$ against a control sample of distilled water [9].

\subsection{Statistical Analyses}

Statistical data processing was performed using the package Statistica 8.0 (StatSoft, Inc., USA). The data for categorical variables are expressed as absolute values and percents, and the data for continuous variables are ex- 
pressed as the median with the $25 \%$ - $75 \%$ inter quartile range. Differences between groups were considered statistically significant at $P<0.05$.

\section{Results}

\subsection{Characteristic of the Patients with Acute Coronary Syndrome}

Repeated coronary events in patients with acute coronary syndrome during the year are presented in Table 1. Unfavorable outcome occurred in 34 (58.7\%) patients. Of them repeated anginal attacks at rest were recorder in $20(58.8 \%)$ patients, repeated or new myocardial infarction in 8 (23.6\%) patients, and coronary death in 6 (17.6\%).

\subsection{Intracellular Metabolism of Neutrophils of the Study Participants}

In patients with acute coronary syndrome in comparison with people without coronary heart disease authentically higher the parameters of the spontaneous NBT-test $(103.6>92.8 \mathrm{mM}$ NBT reduced; $P=0.02)$ and lower activity of glutathione reductase $\left(42.7<67.7 \mathrm{nM} \cdot l^{-1} \cdot \sec ^{-1} ; P=0.003\right)$ at neutrophils were observed (Table 2). Also in patients with acute coronary syndrome the parameters of the stimulated NBT-test were higher (116.3 > 109.2 mM NBT reduced), that testifies not only activation of NAD(P)H oxidase and production of superoxide anion, but the changes of structure glycoprotein receptors on surface of plasmatic membrane of neutrophils.

\subsection{Intracellular Metabolism of Neutrophils in Dependence from Repeated Coronary Events in Patients with Acute Coronary Syndrome}

At studying intracellular metabolism of neutrophils in process of weighting unfavorable outcome not only activation of production of superoxide anion radicals and more the prompt reply to stimulus of neutrophils, but also decrease in activity of antioxidative enzymes in cell were observed. The greatest changes intracellular metabolism of neutrophils in patients with fatal outcome during the year was revealed. In the given patients the decrease of glutathione reductase $\left(13.3<57.1 \mathrm{nM} \cdot l^{-1} \cdot \mathrm{sec}^{-1}\right)$ and catalase activity $(424.4<522.2 \mathrm{mCat} / \mathrm{l})$ was accompanied by the greatest growth of $\mathrm{NAD}(\mathrm{P}) \mathrm{H}$ oxidase activity according to the parameters of the spontaneous (114.7 > 100.4 mM NBT reduced) and stimulated NBT-test (138.8 > 106.1 mM NBT reduced), and myeloperoxidase activity (19.4 > 15.5 SED) at neutrophils (Table 3 ).

Table 1. Repeated coronary events in patients with acute coronary syndrome.

\begin{tabular}{cc} 
Parameter & Acute coronary syndrome $(\mathrm{n}=58)$ \\
Repeated coronary events & $34(58.7)$ \\
Repeated anginal attacks & $20(58.8)$ \\
Myocardial infarction & $8(23.6)$ \\
Cardiac death & $6(17.6)$ \\
\hline
\end{tabular}

Table 2. Intracellular metabolism of neutrophils of the study participants.

\begin{tabular}{|c|c|c|c|}
\hline Parameter & No coronary heart disease $(n=50)$ & Acute coronary syndrome $(n=58)$ & $P$ \\
\hline Spontaneous NBT-test, mM & $92.8(75 ; 111.3)$ & $103.6(90 ; 118.5)$ & 0.02 \\
\hline Stimulated NBT-test, mM & $109.2(105.4 ; 117.3)$ & 116.3 (101.7; 133.1) & $>0.05$ \\
\hline Myeloperoxidase, SED & $15.3(11.5 ; 17.9)$ & $14.5(7.5 ; 22)$ & $>0.05$ \\
\hline Glutathione reductase, $\mathrm{nM} \cdot \mathrm{l}^{-1} \cdot \mathrm{sec}^{-1}$ & $67.7(26.8 ; 80.4)$ & $42.7(12.6 ; 59.8)$ & 0.003 \\
\hline Catalase, mCat/l & 494.1 (359.6; 532.8) & 484.7 (313; 607.3) & $>0.05$ \\
\hline
\end{tabular}


Table 3. Intracellular metabolism of neutrophils in patients with acute coronary syndrome.

\begin{tabular}{ccccc}
\hline Parameter & $\begin{array}{c}\text { Favorable outcome } \\
(\mathrm{n}=24)\end{array}$ & $\begin{array}{c}\text { Repeated anginal attacks } \\
(\mathrm{n}=20)\end{array}$ & $\begin{array}{c}\text { Myocardial infarction } \\
(\mathrm{n}=8)\end{array}$ & $\begin{array}{c}\text { Coronary death } \\
(\mathrm{n}=6)\end{array}$ \\
\hline Spontaneous NBT-test, $\mathrm{mM}$ & $100.4(87.4 ; 119.9)$ & $103.1(89.7 ; 113.8)$ & $106.3(99 ; 116)$ & $114.7(109.9 ; 118.5)$ \\
Stimulated NBT-test, mM & $106.1(93.8 ; 118.5)$ & $121.2(104.5 ; 135.1)$ & $123.4(114.6 ; 133.1)$ & $138.8(124.9 ; 152.7)$ \\
Myeloperoxidase, SED & $15.5(8.5 ; 22.5)$ & $12.9(7.1 ; 18.3)$ & $11.6(5.7 ; 14.1)$ & $19.4(12 ; 25.1)$ \\
Glutathione reductase, $\mathrm{nM} \cdot \mathrm{l}^{-1} \cdot \mathrm{sec}^{-1}$ & $57.1(15.9 ; 77.1)$ & $35.1(3.9 ; 43.8)$ & $48.7(33.2 ; 66.5)$ & $13.3(7.9 ; 18.6)$ \\
Catalase, mCat/l & $522.2(350.9 ; 696.5)$ & $492.3(303 ; 686.6)$ & $398.2(243.7 ; 491.4)$ & $424.4(313 ; 414.2)$ \\
\hline
\end{tabular}

\section{Discussion}

For today the doctrine about phagocytosis is a set of representations about the free and fixed cells of marrow which possessing powerful cytotoxic potential, exclusive reactance and high mobilization readiness are the first line of mechanisms immunological homeostasis. Among phagocytes the most mobile cells are neutrophils which before all are involved in any inflammatory process. However phagocytes in struggle for constancy of the internal environment of organism are capable not only to destroy microbes, but also to damage own tissue under certain conditions [5].

Connection of neutrophils to damage of myocardium begins with the first minutes after occlusion of coronary artery [10]. At reperfusion of the myocardium the adhesion of neutrophils to endothelium of coronary arteries leads to the development of the "no-reflow phenomenon" capillaries including collaterals. Production of destructions factors in neutrophils quickly accrues at their migration from vessels in myocardium that results to its damage [11]. At autopsy of patients with acute myocardial infarction was revealed that neutrophil infiltration of coronary arteries is actively associated with acute coronary events [12]. Believe that neutrophils exert an aggravating effect in arrhythmogenesis during ischemia/reperfusion, and inhibition of neutrophils accumulation can at least partially reduce arrhythmogenesis [13].

The brightest display of reactance neutrophils is the production of reactive forms of oxygen by means of which cells carry out the functions of effector. Reactive oxygen species initiate the process non fermentative peroxide oxidation. Uncontrollable formation of products peroxide oxidation in neutrophils can promote destruction of cellular membranes of phagocytes and damage of muscular tissue. The process of reactive oxygen species production in neutrophils is supervised by the ramified system antioxidative protection which functional full value substantially determines current of disease and probability of recovery [14]. The meta-analysis of numerous researches testifies the reduction of antioxidative protection in patients with coronary heart disease and its risk factors [15].

In the given research the development of fatal outcome in patients with acute coronary syndrome associated with the decrease of activity of glutathione reductase and catalase in neutrophils. The revealed reduction antioxidative protection of neutrophils in patients with coronary death was observed on background of increase of activity NAD(P)H oxidase and myeloperoxidase at cells that could promote destabilization of cells and development of endothelial dysfunction. It is possible, that in comparison with other patients with acute coronary syndrome the people with fatal outcome had additional factors of activation of oxygen-dependent metabolism of neutrophils which promoting the greater exhaustion antioxidative protection.

\section{Conclusion}

Thus, the decrease of activity of antioxidative enzymes (glutathione reductase and catalase) at neutrophils in patients with acute coronary syndrome associates with risk of fatal outcome in during the year.

\section{References}

[1] Heitzer, T. (2003) Clinical Effects of Free Radical Scavengers. Heart Metabolism, 19, 11-17.

[2] Sato, H., Jordan, J.E., Zhao, Z.Q., Sarvotham, S.S. and Vinten-Johansen, J. (1997) Gradual Reperfusion Reduces Infarct Size and Endothelial Injury but Augments Neutrophil Accumulation. The Annals of Thoracic Surgery, 64, 10991107. http://dx.doi.org/10.1016/S0003-4975(97)00734-0 
[3] Kyne, L., Hausdorff, J.M., Dukas, L., Azhar, G. and Wei, J.Y. (2000) Neutrophilia and Congestive Heart Failure after Acute Myocardial Infarction. American Heart Journal, 139, 94-100. http://www.ncbi.nlm.nih.gov/pubmed/10618568?access_num=10618568\&link_type=MED\&dopt=Abstract

[4] Schachinger, V., Britten, M.B. and Zeiher, A.M. (2000) Prognostic Impact of Coronary Vasodilator Dysfunction on Adverse Long-Term Outcome of Coronary Heart Disease. Circulation, 101, 1899-1906. http://circ.ahajournals.org/content/101/16/1899 http://dx.doi.org/10.1161/01.CIR.101.16.1899

[5] Kratnov, A.E. (2014) Role of Neutrophils in Development of Endothelial Dysfunction at Coronary Heart Disease. In: Keaton, T.H., Ed., Endothelial Dysfunction: Risk Factors, Role in Cardiovascular Diseases and Therapeutic Approaches, Nova Science Publishers, Inc., New York, 113-122. https://www.novapublishers.com/catalog/product_info.php?products_id=50213

[6] Gentle, T.A. and Thompson, R.A. (1990) Neutrophil Function Tests in Clinical Immunology. In: Gooi, H.G. and Chapel, H., Eds., Clinical Immunology. A Practical Approach, 2nd Edition. Oxford University Press, New York, 5759.

[7] Saidov, M.Z. and Pinegin, B.V. (1991) Spectrophotometric Analysis of Myeloperoxidase Activity in Phagocytes. Laboratornoe delo, 3, 56-59.

[8] Kratnov, A.E., Potapov, P.P., Vlasova, A.V., Uglov, E.S. and Sukhorukov, V.S. (2005) The Activity of Glutathione Reductase in Neutrophils of Patients with Mucoviscidosis. Klinicheskaia laboratornaia diagnostika, 2, 33-36. http://scholar.qsensei.com/content/11s7vg

[9] Mamontova, N.S., Beloborodova, E.I. and Tucalova, L.I. (1994) Activity of Catalase at Chronic Dipsomania. Klinicheskaia laboratornaia diagnostika, 1, 27-28.

[10] Mehta, J., Dinerman, J., Mehta, P., Saldeen, T.G., Lawson, D., Donnelly, W.H. and Wallin, R. (1989) Neutrophil Function in Ischemic Heart Disease. Circulation, 79, 549-556. http://circ.ahajournals.org/content/79/3/549 http://dx.doi.org/10.1161/01.CIR.79.3.549

[11] Jordan, J.E., Zhao, Z.-Q. and Vinten-Johansen, J. (1999) The Role of Neutrophils in Myocardial Ischemia-Reperfusion Injury. Cardiovascular Research, 43, 860-878. http://dx.doi.org/10.1016/S0008-6363(99)00187-X

[12] Naruko, T., Ueda, M., Haze, K, van der Wal, A.C., van der Loos, C.M., Itoh, A., Komatsu, R., Ikura, Y., Ogami, M., Shimada, Y., Ehara, S., Yoshiyama, M., Takeuchi, K., Yoshikawa, J. and Becker, A.E. (2002) Neutrophil Infiltration of Culprit Lesions in Acute Coronary Syndromes. Circulation, 106, 2894-2900. http://www.ncbi.nlm.nih.gov/pubmed/12460868 http://dx.doi.org/10.1161/01.CIR.0000042674.89762.20

[13] Dhein, S., Schott, M., Gottwald, E., Müller, A. and Klaus, W. (1995) The Contribution of Neutrophils to Reperfusion Arrhythmias and a Possible Role for Antiadhesive Pharmacological Substances. Cardiovascular Research, 30, 881-888. http://www.ncbi.nlm.nih.gov/pubmed/8746202

[14] Miller, N.J., Johnston, J.D., Collis, C.S. and Rice-Evans, C.A. (1997) Serum Antioxidant Activity after Myocardial Infarction. Annals of Clinical Biochemistry, 34, 85-90. http://dx.doi.org/10.1177/000456329703400113

[15] Flores-Mateo, G., Carrillo-Santisteve, P., Elosua, R., Guallar, E., Marrugat, J., Bleys, J. and Covas, M.-I. (2009) Antioxidant Enzyme Activity and Coronary Heart Disease: Meta-Analyses of Observational Studies. American Journal of Epidemiology, 170, 135-147. http://aje.oxfordjournals.org/content/170/2/135.full http://dx.doi.org/10.1093/aje/kwp112 